\title{
The Attainability of Sustainable Development by Implementing a Diversification Strategy at the Infectious Diseases Institute (IDI) in Uganda (East Africa) in Relation to Global Education, Research and Technology
}

\author{
Article by Bombo Henry Lubega \\ PhD Management, Texila American University, Uganda \\ E-mail:bombohenry@gmail.com
}

\begin{abstract}
From the global point of view, sustainable development based research and education is the back bone of any nation. In addition, sustainable development policies following millennium development goal highlights the role of education and technology which has become the need of the day to create the awareness among the citizen, researchers and policy makers as well as in local communities for environment protection concept. The present paper gives an overview regarding the contribution, research and technology in the development of an Institute in sustainable manner. Sustainable Development is an idea of education which aims to empower the individuals to assume liability to build a sustainable future.

From the micro point of view, this zeros down to the impact of implementing a diversification strategy at the infectious diseases institute to ensure sustainability and this is guided by three research questions. To establish the strategies implemented by IDI, to evaluate the effectiveness of the strategies implemented by IDI \& to establish the Link between the strategies implemented \& competitive advantage. The researcher adopted a descriptive \& exploratory research designs. The respondents were selected using purposive and stratified random sampling techniques. Data gathered through Questionnaires and interview guides administered to respondents. The SPSS technique was used to establish the link between strategies implemented \& competitive advantage.

In conclusion, this research found out that the strategy is initiated by identifying existing resources and expertise in the organization followed by the assessment of sustainability of competitive advantage that they can provide. Other researchers have suggested that firms may improve efficiency of their operations through various related diversification approaches because of growing economies of scope that allow for the joint development and utilization of firm-specific skills.
\end{abstract}

\section{Introduction}

This chapter gives details and description of Sustainable development in relation to Uganda, the global point of view, general outlook, specific areas of analysis, research questions and conceptual frame work.

\section{Sustainable development in detail in relation to uganda}

Sustainable development is a process which involves human's intelligence, decision making efficiency, planning and management skills, power of imagination, entrepreneurship, development and production with environmental safety etc. Usually, sustainable development is a human subject. The issue associated with sustainable development can be seen as one of the basics of any society (Hopkins, and McKeon 1999).

For over 50 years, scientist and other thought leaders have been trying to call attention to the degradation of the foundation for human civilization through unsustainable behavior (Carson 1962, Meadows et al. 1972, Steffen et al.2004, Millennium Ecosystem Assessment 2005, Stern 2007, Intergovernmental Panel on Climate Change 2007, Rockström et al. 2009). What started out with the environmental movement in the 1960s slowly became a broader movement that acknowledged the interveners of people's ecological, social and economic well-being (McKenzie 2004, Cuthill 2010). 
Sustainable development (SD) most prominently entered the global political arena in 1987 in a report from the United Nations Commission on Environment and Development, also known as the Brundtland report. The report stated Humanity has the ability to make development sustainable - to ensure that it meets the needs of the present without compromising the ability of future generations to meet their own needs (World Commission on Environment and Development 1987). In 1992, at the Earth Summit in Rio de Janeiro was adopted as the universal definition of sustainable development and has since been the basis for various discussions in the international policy arena, such as the World Summit on Sustainable Development in Johannesburg in 2002 and the Rio+20 conference in Rio de Janeiro in 2012, as well as efforts on a regional level to put this idea into practice, e.g., Agenda 21 (Cuthill 2010).

There has been much criticism of the Brundtland definition, mainly in relation to the vagueness of what sustainability and sustainable development actually mean (Jacobs 1999, McKenzie 2004). Paehlke (2001, as cited in Partridge2005) argues that sustainable development is a concept so amorphous that it might mean anything. Jacobs (1999) notes, the vagueness of the definition allows business and 'development' interests (and their government supporters) to claim that they are in favor of sustainable development when actually they are the perpetrators of unsustainably.

The vagueness has also led to a vast array of ideas, concepts, methods and tools to aid organization sand governments to address the socio-ecological problems. This variety of definitions, terms, approaches, methods and tools, many of them designed for specific fields only, makes the sustainability field confusing and leads to a growing need to understand how they relate to sustainability and to each other (Huesemann 2001, Robèrt et al. 2002).

The Rio de Janerio Earth Summit in 1992 adopted Agenda 21 and the Action Plan of $21{ }^{\text {st }}$ Century. The main object of the agenda is to address the concerns of ensuring that society takes into account that development needs to be sustainable to meet the needs of the present generations without jeopardizing the chances of future generations to meet their own. UNESCO was charged with the responsibility for implementing chapters 35 and 36 of Agenda 21: Science for Sustainable Development and, Promoting Education and technology, Public Awareness and Training respectively. Chapter 36 notes that besides being a fundamental right, Education and technology is critical for promoting sustainable development and improving the capacity of the people to address environment and development issues.

The Johannesburg World Summit on Sustainable Development, 2002 acknowledged that some progress had been made in commitments to sustainable development. It also re-affirmed the determination to promote the three pillars of sustainable development, namely: economic development, social development and safeguarding of the environment.

The summit also regrettably noted however, that little progress had been made in achieving sustainable development through education and technology. It therefore named education and technology as the key to creating public awareness, and training for moving society sustainably to ensure sustainable development. It also noted that if education and technology was not 2 consciously re-oriented and consciously planned towards sustainable development, the world would miss out on achieving the Millennium Development Goals (MDGS) as well as the Education and technology for All (EFA) Goals

In Uganda, the Government has developed this strategy to address the challenges of implementing the United Nations Decade of Education and technology for Sustainable Development. The document is a collective effort of many stakeholders in education and technology, environment, society and the economy disciplines.

The strategy takes into account the national aspirations and goals as spelt out in key instruments like the Constitution of Uganda, The Vision 2035, the National Development Plan, the Education and technology (2008) Act, the National Environment Act and the various sectorial strategies. These instruments address in different ways issues of the environment, economy and society, which are the key pillars of Education, Research and Technology for Sustainable Development (ERTSD). The Constitution for example, commits itself to building a just and fair society. The National Environment Act guarantees 
the right to a clean and healthy environment, while the Education and technology Act ensures a right to education and technology. All these invariably lead to ensuring rights based approach to development.

In Uganda the strategy also recognizes the already existing initiatives being implemented by various actors and partners, which may not necessarily be called ERTSD but, address issues of sustainable development. Unfortunately, many of these initiatives are not known to many actors in ERTSD, yet the country is facing complex environmental problems, caused by increasing population together with increased development that have both resulted in environmental degradation. There is need for research about the contribution of education, research and technology to capture all these initiatives under one major document to help in entrenching sustainable development in worldwide including Uganda.

\section{Global sustainable development}

Globally United Nations defines Global Sustainable Development as development that meets the needs of the present without compromising the ability of future generations to meet their own needs (Cleveland, and Kubiszewski, 2007). Globally sustainable development is a pattern of using natural resources in such a way which provides regular individual requirements considering the preservation of the environment for coming generations (Forum for the Future, 2003). The world's population including is predicted to experience the growth/increase from six to nine billion between the years 2000 to 2050, with significant transformations in economic growth, international relations, human development, biodiversity, human health, and social justice(Forum for the Future, 2003). Despite the fact that, the employers and policy makers increasingly need manpower and technology to enable these national and global challenges associated with increasing population, economic growth, international relations, biodiversity, and human development. Less has been documented about the contribution of education, research and technology on sustainable development. It is against this context that the need to carry out this study is necessary.

\section{The general outlook}

The general outlook gears towards the contribution of education, research and the new technology for sustainable development in Uganda.

\section{Specific areas of analysis}

1) To examine the relationship between Education and the sustainable development in Uganda

2) To examine the relationship between research and the sustainable development in Uganda

3) To assess the relationship between technology and the sustainable development in Uganda

\section{Research questions at play}

1) What is the relationship between Education and the sustainable development in Uganda

2) What is the relationship between research and the sustainable development in Uganda?

3) What is the relationship between technology and the sustainable development in Uganda? 
6DOI: $10.21522 /$ TIJMG.2015.03.02.Art026

ISSN: $2520-310 \mathrm{X}$

\section{Conceptual framework}

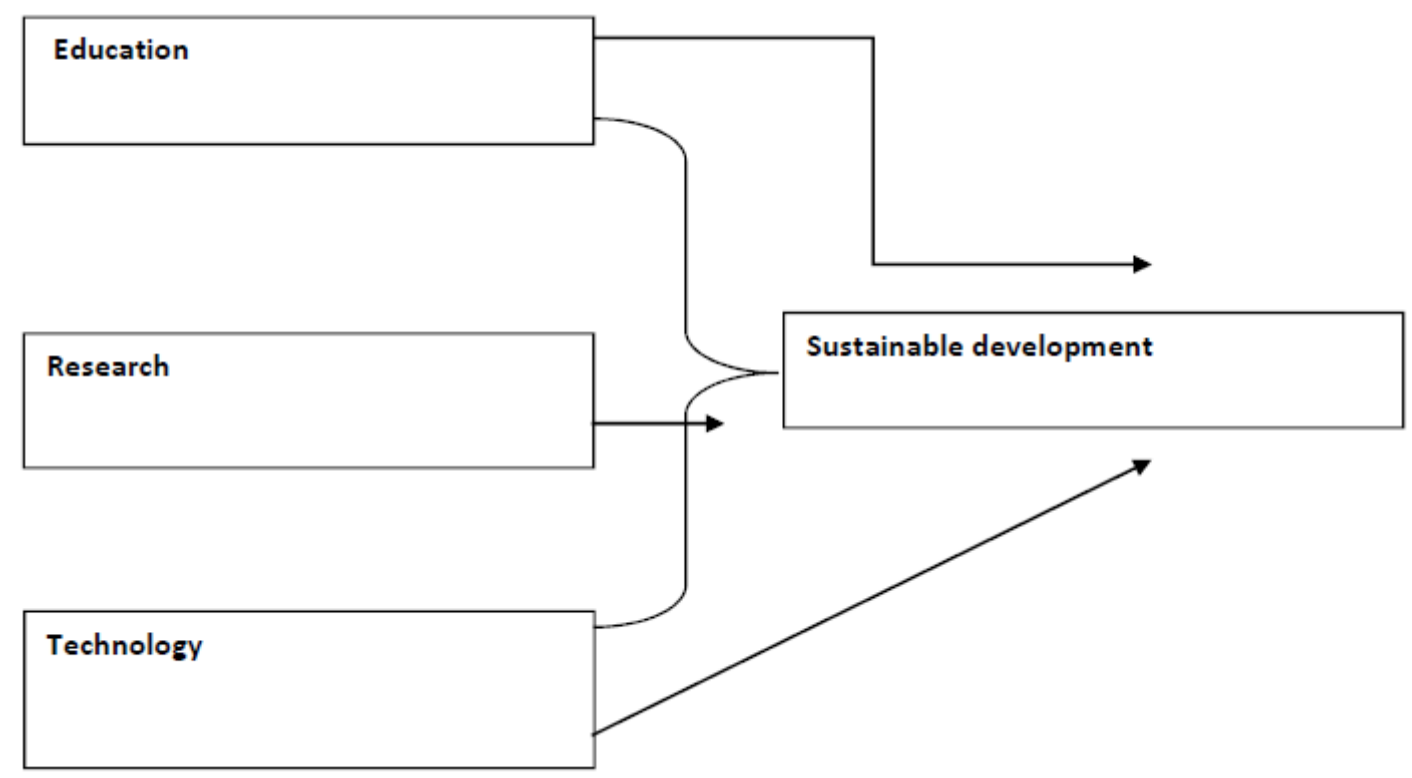

The researcher's own adaptation of the conceptual model shown in Figure 1 above demonstrates the influence of education, research and technology on sustainable development $\mathrm{o}=$ in developed and developing world. Education, research and technology (independent variables) influence sustainable development (dependent variable) as shown by the arrows. It shows that there is a way independent variable relates to dependent variable to bring about sustainable development in developed and developing world including Uganda. The link between them shall be stipulated well in the next chapter (chapter two literature reviews).

\section{Sustainable development by implementing a diversification strategy at the infectious diseases institute (IDI) in Uganda (East Africa)}

\section{(i) Back ground to the study}

Infectious Diseases Institute (IDI) as a not for profit organization limited by guarantee depends on donor funds to support its core activities and invest in various projects including research and capacity development.

When IDI was founded in 2002 it received support from Pfizer Inc. which contributed \$ $3 \mathrm{~m}$ per year to cover IDI's core costs until in the last five years when this funding was reduced to $\$ 0.6 \mathrm{~m}$ per year until it eventually stopped in 2012.

IDI has developed a strong funding base along the years. In the financial year ended 2013,51 percent of IDI's funds were from Centers for Disease Control (CDC) and the 49 percent was made up of funds from; the United States National Institute of Health (NIH), Civil Society Fund (CSF),European Union (EU), Accordia, Gates Foundation, Unites States Agency for International Development (USAID), Government of Uganda and others. Whereas CDC made the largest contribution to IDI, their funds are restricted as they do not support IDI's core costs.

Also in the year 2013, funding for global HIV and AIDS response reached its highest ever level with an estimated \$ 19.1 billion made available for programs in low and middle income countries(UNAIDS \& The Henry J. Kaiser Family Foundation 2014).

In the same vain global HIV spending stagnated and even declined in areas such as HIV prevention research and development (R \& D). Between 2012 and 2013, funding for HIV prevention R \& D fell by 4 percent. This fall was mainly the result of declining US investment which funds roughly 70 percent of the 
total global investment into HIV prevention R \& D. Investment from European funders as well as philanthropic ones also fell.

With the increasing world recession, there have been funding cut backs in addition to increased number of upcoming Non-Government Organizations that have taken interest in HIV/AIDs related activities and this poses the questions about the long term survival of the Infectious Diseases Institute.

According to the global fund strategy 2012-2016, there has been a shift from funding HIV/AIDS and infectious diseases to other infections including neglected tropical diseases, Hepatitis B \& C, 7 diarrhea diseases in children and a growing emphasis on funding to combat non communicable diseases such as hypertension and heart disease.

In order to achieve IDI's goal of "strengthening health systems in Africa, with a strong emphasis on infectious diseases, through research and capacity building", the institute needs to have a strong base of both financial and human resources so as to support the institute's core activities and ensure long term survival of the organization.

Failure to secure funding could lead to closure of the institution, lost capacity and unexpected unemployment.

Given the current economic uncertainty, not for profit organizations must be innovative in how to attract revenue. This means widening the scope of existing business and area coverage for not for profit organization so as to survive.

\section{(ii) Case Study report}

\section{Proposition 1: IDI has fluctuating sources of funding}

IDI's funding base has been increasing both in breadth of funded projects and the volume of funding. In year ended June 2011, the number of externally funded projects increased from 60 to 71 projects with a funding value of \$ 31 and in the year ended June 2012 IDI had 83 externally funded projects with a value of $\$ 26$ million. IDI funding base was maintained for the year ended June 2013 but with much difficulty for IDI since the unrestricted funding from Pfizer had drawn to a conclusion along the year.

Below is a graphical presentation of the funding sources for IDI for the last three years.

\section{Graph}

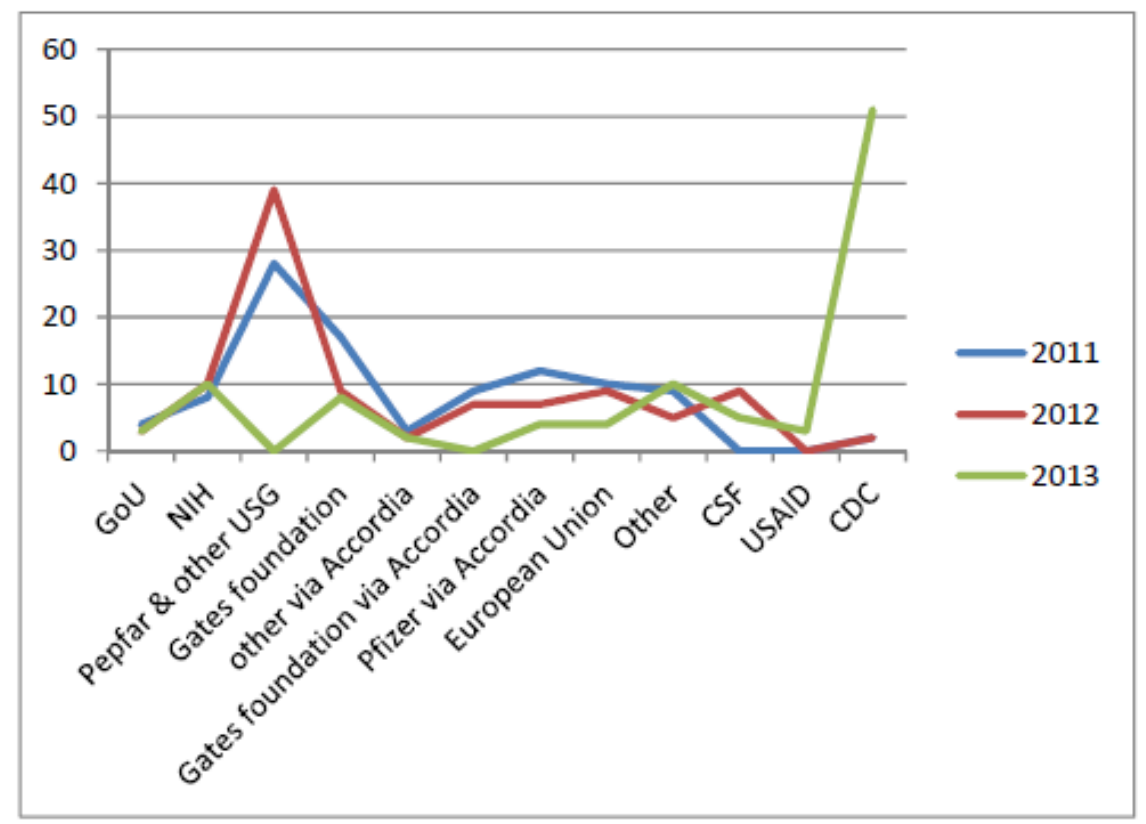


6DOI: $10.21522 /$ TIJMG.2015.03.02.Art026

ISSN: $2520-310 \mathrm{X}$

\section{Proposition 2: IDI does not have a diversification strategy to enable it acquire funding from various sources}

IDI is a not for profit institute with a mission to strengthen health systems in Africa with a strong emphasis on infectious diseases through research and capacity development is donor funded.

This kind of mission is the driving force and gives characteristics to the kind of grants that IDI applies for thus the limitation in scope.

\section{IDI's current services}

- Prevention, Care and Treatment: The prevention, care and treatment program runs the adult infectious diseases clinic at IDI and provides HIV/AIDS care services.

- Research: The research program at IDI focuses on identifying best practice models for prevention, care and treatment of HIV/AIDS and related infectious diseases in Africa.

- Training and capacity development: IDI's training program was established to provide advanced and specialized courses including technical support in the management of HIV/AIDS and other infectious diseases.

- Laboratory services: The goal of the laboratory services program at IDI is to develop and continually improve sustainable laboratory capacity at IDI to meet both clinical and research demands for laboratory services from IDI, Uganda and Africa as a whole.

- Outreach: The scope of IDI outreach activities run across;

- HIV,TB, malaria and MCM in both urban and rural areas

- A spectrum of types of services from health promotion/disease prevention through to curative referral services

- All levels in the health system from the grass root community (through support to village health workers) to eight regional referral hospitals.

\section{SWOT Analysis}

\section{Strengths}

- Governance structure (independent board) within makerere university

- Strong partnerships with and complementarity to MoH, MoE and UAC

- Integrating and interrelationship of quality PCT, research, training and capacity development, laboratory and outreach.

- Strong support systems (for example IT, grants management and finance).

- Firm links with many reputable national and international organizations.

\section{Weaknesses}

- Limited collaborations with non-English speaking countries

- Some internal systems have become slow, bureaucratic and risk averse

- Insufficient demonstrated impact to date on national policy given the large amounts of research and capacity building carried out.

- Partnerships with some local institutions need to be strengthened.

\section{Opportunities}

- Additional collaboration and funding from national and, regional and international partnerships.

- Expanding current joint collaborations with Makerere University, Mulago hospital and Ministry of Health

- Strengthening of regional dimension to IDI programmes and linkage with East African community

- Attract new grants for health system strengthening. 


\section{Threats}

- World recession leading to funding cutbacks by governments and private donors

- Funders' rules becoming more constraining as IDI seeks to cover core costs for project income.

- Shift in global funding priorities away from HIV/AIDS and related infectious diseases towards other health priorities

- Weak health systems that will not provide a good quality platform for IDI's work to make an impact

- The global image of Uganda (relative to corruption and human rights) will have an impact on IDI.

\section{Problem statement}

The sustainability \& survival of many NGOs in Uganda, IDI inclusive has been greatly challenged in the recent years due to lack of funds and uncertainty of the funding environment. Because of this threat, sustainability is nowadays a donor's requirement and NGOs which do not have the element of sustainability in their project design and implementation most likely do not attract funding from donors. Yet very little has been done in this area and policy makers have not done much to reduce the problem of failure to sustain projects

Available research by the European Commission (2006) concentrated on sustainability of international cooperation projects in the field of higher education and vocational training but with no emphasis on health related NGOs like IDI. This research therefore current research will focus on community involvement and sustainability of Bunyoro HIV project in Hoima.

\section{Purpose \& rationale of the study}

The purpose of the study was to examine examining the challenges to sustainability at IDI and the different methods of diversification that can be applied to reduce the uncertainty about the organization's survival. It also sought to establish the relationship between the diversification strategy and sustainability of IDI

\section{Research questions}

i) What are the challenges to sustainability at the Infectious Diseases Institute?

ii) What are the different methods of diversification?

iii) Is there a relationship between diversification strategy and sustainability?

\section{Methodology}

This study adopted a cross-sectional research design or survey. The justification is that, it tends to collect first hand and in-depth data from various respondents at a given point in time. The design is advantageous because it offers the ability to provide a "snapshot" of the phenomenon under study with a minimum cost and takes little time to conduct and determines the degree of relationship between variables in the study (Amin, 2005; Annet N \& Phillips J, 2009; Sobol J.J, 2014). Information on the target population was gathered at a single point in time from a cross-section of respondents in all IDI departments. An Exploratory research design was also used in the study. It was deemed appropriate because helps to determine the present facts as well as facts that are not yet explored about the phenomena. It was used by the researcher to explore the views of different set of respondents, as well as exploring different literatures related to the study.

An evaluative research design was also used to study the effects of the different diversification strategies on IDI sustainability levels \& the associational research design was also used to help in establishing whether there's a relationship between diversification strategy and sustainability of the Infectious Diseases Institute. 
6DOI: $10.21522 /$ TIJMG.2015.03.02.Art026

ISSN: $2520-310 \mathrm{X}$

\section{Content analysis}

This involves a detailed and systematic of examination of the contents of a particular body of material for example books, published journal articles, legal documents, internet blogs and bulletin board entries for purposes of identifying patterns, themes or biases.

The researcher examined 30 journal articles that are available on the internet so as to get a broad view of the topic of the impact of implementing a diversification strategy on the financial sustainability of an organization from different scholars.

The researcher selected content analysis since the study is qualitative and the topic of study has been discussed by several researchers and academicians.

\section{Case study}

The researcher used a case study design to examine the composition of IDI's funding base from the time it was formed to date. IDI's problem is having limited sources of funding and the student feels that the case study design will be of help to sort this phenomenon.

The researcher identified the strengths, weaknesses, opportunities and threats of IDI

Yin 2003 states that a case study design should be used when there is need to answer how and why questions in a given situation.

The case study design provided the researcher with a deeper understanding of the issue at hand.

\section{Case study propositions}

Table 1.

\begin{tabular}{|l|l|l|}
\hline 1 & Propositions & Source \\
\hline 2 & $\begin{array}{l}\text { IDI has fluctuating sources of funding } \\
\text { strategy to enable it acquire funding } \\
\text { from various sources }\end{array}$ & $\begin{array}{l}\text { Review of annual report documents } \\
\text { documents of IDI, professional } \\
\text { experience }\end{array}$ \\
\hline
\end{tabular}

The study focused on employees of IDI with a target population of 34 respondents consisting of the IDI board Chairman, Executive Director, Six (6) Heads of department \& (6) deputy heads of departments, Ten (7) Project Managers, four (5) project Administrators, and Ten (10) subordinate staff.

The study adopted two sampling methods which will include; Purposive sampling and Simple random sampling. The purposive sampling was used in the selection of key informants in the study because of the role they play in strategy formulation based on their knowledge and experience. It was used in selecting respondents such as Board Chairman, executive director, heads of departments, project Managers and other top administrators. Simple random sampling was also used to select the respondents from a list of subordinates. This method was used because it gives each member in the study population an equal independent chance of being selected or it provides the best opportunity to generalize the results to the entire population there by reducing the chances of bias (Mugenda \& Mugenda,2003)

The researcher also obtained a sample of 30 journal articles from EBSCOHOST library. These provided the context about diversification strategy and sustainability.

Both primary and secondary data were used to enable the collection of proper, relevant and comprehensive data. Questionnaires were structured on the basis of the research questions, \& presented to respondents to express their views, opinions, and observations. Interviews were also conducted in order to get detailed data from the top \& middle level administrators (supervisors) and a few of the subordinate staff with the help of interview guides. The method was adopted because it enables to probe and seek further clarification about the research topic from the key informants, provides an 
opportunity to the researcher to observe as well as listen and provides in-depth information hence ensuring reliability of the data (Doody O \& Noonan M (2013)

\section{Document review}

This method was used to obtain secondary data from the existing documents like reports, minutes among others. This method was considered because of the readily available data for reference. The researcher reviewed published journals, newsletters, annual reports and text books regarding diversification strategy and sustainability.

The reason for reviewing existing documents as a research instrument was that it will provide the background and context surrounding the study topic. It also gave an insight to the researcher about the views of the different scholars and specialists of that particular topic.

Data was presented and analyzed using quantitative and qualitative approaches. This meant making it error free to ensure accuracy, uniformity and completeness. Qualitative data was collected and recorded during face to face sessions. The information was analyzed thematically so as to simplify its organization, categorization, retrieval and establish meaningful themes of relationships between the data and the study problem

Quantitative data was collected using data collection instruments like questionnaires. After checking the completeness and coding of the open ended questionnaires, the data was critically checked and analyzed using tables with calculated values consisting of frequencies \& percentages to draw meaningful research patterns interpretation and conclusions. This was used to supplement qualitative data. Data was analyzed using computer software known as Statistical Package for Social Scientists - SPSS.

\section{Measurement of variables}

In quantitative method of data collection, the Likert scale was used to measure variables under the study. The Likert scale was designed with five categories of response columns of strongly disagree, Disagree, Non-committal, Agree, Strongly agree. The respondents were required to select the responses that best described their opinions to each question. The response category was weighed ranging from 1-5. This choice of measurement was made because it made it easier for the respondents to express their opinion by checking the value from 1-5 respectively. For the main variables, ordinal scale was considered. This is because all these variables were ranked from highest to lowest Likert scale hence the variables.

\section{Results and discussions}

\section{Findings on the challenges to sustainability at the infectious diseases institute}

In order to determine the challenges to sustainability at the Infectious Diseases Institute Makerere University, respondents were asked on several variables. These variables were, what is your level of seniority at IDI, Are you aware that IDI is financially constrained at the moment? What is the main reason behind this, do you see IDI thriving in the NGO environment with same mission in the next five years? These variables were very important in the determination of the challenges to sustainability at the Infectious Diseases Institute. The findings are presented below on table 4-5

Table 4-6. Challenges to sustainability at the infectious diseases institute

\begin{tabular}{|l|l|l|}
\hline Challenges & Frequency & Percentage (\%) \\
\hline $\begin{array}{l}\text { Uncertainty in donor funding } \\
\text { environment }\end{array}$ & 17 & 61 \\
\hline $\begin{array}{l}\text { Failure to adhere to the } \\
\text { strategic plan \& direction }\end{array}$ & 7 & 25 \\
\hline High Staff turn over & 4 & 14 \\
\hline
\end{tabular}


6DOI: $10.21522 /$ TIJMG.2015.03.02.Art026

ISSN: $2520-310 \mathrm{X}$

\begin{tabular}{|l|l|l|}
\hline Total & 28 & 100 \\
\hline
\end{tabular}

Source: field data

From the table above, $60 \%$ cited uncertainty in donor funding environment, $25 \%$ cited Failure to adhere to the strategic plan \& direction and another 10\% reported High Staff turn over

Findings on the different methods of diversification that are applied to reduce the uncertainty about the organization's survival

Here respondents were asked several questions on diversification and the organizational survival of Infectious Diseases Institute Makerere University. The variables were very important in the determination of different methods of diversification that were applied to reduce the uncertainty about the organization's survival. The different methods of diversification identified were; revenue diversification, project diversification, research diversification and Training and Capacity Development diversification. The findings are presented below on table 4-6

Different methods of diversification that are applied to reduce the uncertainty about the organization's survival

\begin{tabular}{|l|l|l|}
\hline $\begin{array}{l}\text { DIVERSIFICATION } \\
\text { METHODS }\end{array}$ & FREQUENCY & PERCENTAGE (\%) \\
\hline Revenue diversification & 8 & 29 \\
\hline Project Diversification & 2 & 6 \\
\hline Research diversification & 10 & 36 \\
\hline $\begin{array}{l}\text { Training and Capacity } \\
\text { Development }\end{array}$ & 8 & 29 \\
\hline Total & $\mathbf{2 8}$ & $\mathbf{1 0 0}$ \\
\hline
\end{tabular}

Source: field data

The table above shows that Revenue Diversification was 29\%. Project Diversification were 6\%, Research Diversification were $36 \%$. The least were those respondents that mentioned Training and Capacity Development diversification accounting for $29 \%$.

\section{Revenue diversification}

The study revealed that $29 \%$ of the respondents identified revenue diversification as the major method of diversification applied by Infectious Diseases Institute Makerere University to reduce the uncertainty about the organization's survival. This was because revenue diversification identified by the researcher has increased viability for the institute. This is in agreement with a recent study by Fred R. David (2008), who used several measures to explore the impact of multiple revenue sources on overall financial health and concluded, despite some data anomalies, that organizations with diversified funding sources are in a stronger overall financial position than those with few funders.

However, in an interview respondents said that not all the consequences of revenue diversification are positive. They argued that while Infectious Diseases Institute Makerere University may ensure its basic survival by finding multiple funders, it also had to deal with the tension between meeting each funder's requirements for accountability and its own desire for autonomy

Furthermore, findings from the interview revealed that when diversification entails self-generated revenues, uncertainty is not necessarily reduced. Respondents further reported that the quest for funding from alternate sources may cause mission displacement, as Infectious Diseases Institute Makerere 
University resources are concentrated on revenue acquisition instead of the real mission of the organization

\section{Project diversification}

The $6 \%$ of respondents from the table that mentioned project diversification said that this was another major method of diversification applied by Infectious Diseases Institute Makerere University to reduce the uncertainty about the organization's survival. This was because the institute was carrying out several projects to support additional research at the Kampala site of a Multi- Center International Trial to obtain and store blood and mucosal specimens in African HIV-1 discordant couples at key points for future validation of correlates identified in SIV macaque model.

In an interview, respondents confirmed that several projects were also being put in place to support the Jinja site of a Multi-Center International Trial to measure the safety and efficacy of antiretroviral therapy in preventing HIV-1 acquisition among heterosexual HIV discordant couples in which the HIV infected partner has a CD4 cell count of at least $250 / \mathrm{mm} 3$ and does not otherwise meet the National guidelines for initiation of antiretroviral therapy.

\section{Research diversification}

This was another diversification method mentioned by respondents. 36\% of the respondents reported that Infectious Diseases Institute Makerere University was diversifying its services by conducting several researches in the field of infectious diseases in Uganda.

In an interview, respondents said that since 2001, IDI has published 245 research articles in peerreviewed journals. As of June 2013, IDI had 48 active research grants and 18 clinical trials all of which has helped the institute to get support and finances from donors.

It was established that because of the research diversification, Infectious Diseases Institute Makerere University was able to conduct a study in the partners ARV Based HIV Prevention in couple's study, a study to optimize targeted delivery and sustained use of ARV based HIV-1 prevention in African HIV-1 serodiscordant couples all of which has helped to reduce the uncertainty about the organization's survival

\section{Training and capacity development}

From the table 4-6 above, $29 \%$ of the respondents reported that training and capacity development was also another diversification measure applied by Infectious Diseases Institute Makerere University to reduce the uncertainty about the organization's survival. This was because each year, IDI was able to train approximately 1,500 health care workers from across Africa in HIV/AIDS and TB co-infection, malaria, lab services, pharmacy, systems strengthening (data management, monitoring and evaluation, grants management), and research capacity building.

The findings further revealed that in 2005, the joint Makerere University-Johns Hopkins University (MU-JHU) laboratory moved to IDI. Respondents reported that every year this lab conducts approximately 160,000 tests

It was further found out that the MU-JHU laboratory at IDI was the first laboratory outside of the United States to be recognized by the Medical Laboratory Observer's Laboratory of the Year Award all of which has been important in ensuring the survival of Infectious Diseases Institute Makerere University

\section{Findings on the relationship between diversification strategy and sustainability of the Infectious Diseases Institute}

In order to establish the relationship between diversification strategy and sustainability of the Infectious Diseases Institute Makerere University, respondents were asked if there is a relationship between the two variables. The findings are presented below on table 4-7. 
6DOI: $10.21522 /$ TIJMG.2015.03.02.Art026

ISSN: $2520-310 \mathrm{X}$

Table 4.7. Correlation between diversification strategy and sustainability

\begin{tabular}{|ll|l|l|}
\hline & & Diversification strategy & Sustainability \\
\hline $\begin{array}{l}\text { Diversification } \\
\text { strategy }\end{array}$ & Pearson Correlation & 1 & $-.330^{* *}$ \\
& Sig. (2-tailed) & & .002 \\
& $\mathrm{~N}$ & 28 & 28 \\
\hline Sustainability & Pearson Correlation & $-.330^{* *}$ & 1 \\
& Sig. (2-tailed) & .002 & \\
& $\mathrm{~N}$ & 28 & 28 \\
\hline
\end{tabular}

**. Correlation is significant at the 0.05 level (2-tailed)

Table 4.7 above shows that there is a significant relationship between diversification strategy and sustainability. This is because $\mathrm{P}(0.002)$ is less in magnitude than $0.05(\mathrm{p}=0.002<0.05)$. Therefore, the null hypothesis is rejected and we conclude that there is a significant relationship between diversification strategy and sustainability of the Infectious Diseases Institute

Respondents in their interview said that because of the different diversification strategies applied by the institute, there has been development of a site office at IDI for the academic Collaboration between the Canadian HIV Trials Network (CTN) and IDI to pursue HIV/AIDS Clinical Trials, Anti-retroviral therapy of AIDS-related Kaposis Sarcoma in Africa and Hepatitis B Virologic Response in HIV Coinfected patients on Treatment with Tenofovir Versus Lamivudine Containing Regimens all of which have attracted adequate funding from partners

The findings also established that because of the research diversification strategies applied by Infectious Diseases Institute Makerere University as the primary target of capacity building activities, this group of researchers has been responsible for the implementation of research pilot studies.

It was further revealed that currently, there are more than $8 \mathrm{PhD}$-level investigators and Masters level $\mathrm{PhD}$ candidates participating. Each investigator is linked to two mentors; a senior investigator from Makerere and one from the RAND Corporation. The project is designed to provide them with tools, training, structural and organizational support, mentorship, and research experience. By the end of the project, it is expected that investigators will be well positioned to successfully compete for external research funding, and to become leaders in social and behavioral HIV research, both regionally and internationally which will lead to sustainability of the Infectious Diseases Institute

The study further revealed that because of the revenue diversification strategies, there is outstanding clinical training available in Uganda where opportunities exist for post-graduate training (fellowships) in Uganda and elsewhere in sub-Saharan Africa. These programmes allow faculty to participate in research programmes as senior investigators.

Respondents further said that because of the research diversification strategies applied by the institute, there has been improvement in training in clinical infectious diseases, microbiology, diagnostic molecular biology, epidemiology, pharmacology, clinical study design, methodology and statistics that prepare participating fellows for careers in academic infectious diseases as teachers, investigators and clinical infectious disease specialists.

\section{Conclusions}

The study revealed a number of challenges hindering sustainability at IDI and these included;

\section{Uncertainty in funding}

It was revealed that uncertainty in funding environment was a major challenge to sustainability at the Infectious Diseases Institute Makerere University. $61 \%$ of the respondents said that the institute was not 
properly funded but rather depended on donor support from outside countries which normally comes late hence affecting the day to day training and research activities of the institute. NGOs are expressing difficulty in finding sufficient, appropriate and continuous funding for their work. They find accessing donors as challenging as dealing with their funding conditions. They perceive there to be certain cartels of individuals and NGOs that control access to donor funds. They have limited resource mobilization skills and are often not looking for funds that are available locally, preferring to wait for international donors to approach them. There is a high dependency of donors and a tendency to shift interventions to match donor priorities. There is a lack of financial, project and organizational sustainability.

\section{Failure to adhere to the strategic plan $\&$ direction}

This was also identified to be another major challenge to sustainability at the Infectious Diseases Institute Makerere University. IDI has no clear strategic plans that guide the organization to know what the objectives are and enable the organization identify the resources needed. Most strategic plans developed are for donor purposes only and do not reflect the actual needs to be addressed by the communities

\section{High staff turn over}

This was another challenge identified in the study. . From the findings, $14 \%$ of the respondents said that Infectious Diseases Institute Makerere University has experienced a serious setback because of continued staff turn overs.

\section{Different methods of diversification that are applied to reduce the uncertainty about the organization's survival}

The different methods of diversification identified were; revenue diversification, project diversification, research diversification and Training and Capacity Development diversification

Revenue diversification; the study revealed that $40 \%$ of the respondents identified revenue diversification as the major method of diversification applied by Infectious Diseases Institute Makerere University to reduce the uncertainty about the organization's survival. This was because revenue diversification identified by the researcher has increased viability for the institute. This is in agreement with a recent study by Fred R. David (2008), who used several measures to explore the impact of multiple revenue sources on overall financial health and concluded, despite some data anomalies, that organizations with diversified funding sources are in a stronger overall financial position than those with few funders.

Project Diversification; the $30 \%$ of respondents from the table that mentioned project diversification said that this was another major method of diversification applied by Infectious Diseases Institute Makerere University to reduce the uncertainty about the organization's survival. This was because the institute was carrying out several projects to support additional research at the Kampala site of a MultiCenter International Trial to obtain and store blood and mucosal specimens in African HIV-1 discordant couples at key points for future validation of correlates identified in SIV macaque model.

Research Diversification; this was another diversification method mentioned by respondents. $20 \%$ of the respondents reported that Infectious Diseases Institute Makerere University was diversifying its services by conducting several researches in the field of infectious diseases in Uganda. In an interview, respondents said that since 2001, IDI has published 245 research articles in peer-reviewed journals. As of June 2013, IDI had 48 active research grants and 18 clinical trials all of which has helped the institute to get support and finances from donors.

It was established that because of the research diversification, Infectious Diseases Institute Makerere University was able to conduct a study in the partners ARV Based HIV Prevention in couple's study, a study to optimize targeted delivery and sustained use of ARV based HIV- 
6DOI: $10.21522 /$ TIJMG.2015.03.02.Art026

ISSN: $2520-310 \mathrm{X}$

\section{Relationship between diversification strategy and sustainability}

Hypothesis testing was done for this objective and findings revealed that there is a significant relationship between diversification strategies implemented and sustainability since the P-value (0.002) is less in magnitude than $0.05(\mathrm{p}=0.002<0.05)$.

Furthermore, respondents in their interview said that because of the different diversification strategies applied by the institute, there has been development of a site office at IDI for the academic Collaboration between the Canadian HIV Trials Network (CTN) and IDI to pursue HIV/AIDS Clinical Trials, Antiretroviral therapy of AIDS-related Kaposis Sarcoma in Africa and Hepatitis B Virologic Response in HIV Co-infected patients on Treatment with Tenofovir Versus Lamivudine Containing Regimens all of which have attracted adequate funding from partners.

\section{Recommendation}

In consistency with the findings and conclusions presented in the above sub sections, the current study makes the following recommendations for ensuring sustainability of NGOs and future studies on the same course

Many resource mobilization efforts of organizations are focused on fund raising from international institutional donors. If organizations desire to diversify their sources of resources, they may have to revise their current approaches, which are only focused on attracting external grants and accommodate options of sourcing resources from businesses and individuals. Private sources allow organizations to respond quickly and they have fewer restrictions.

The study suggests that the NGOs should appreciate competition as its becoming a common phenomenon in the external funding environment. Though competition has been used extensively in the private sector, collaboration may be suitable in the social services sector. However, understanding organizations within one's sector or other sectors should be an integral part of IDI's environmental scan.

The study, suggest for applying innovative approaches to retain the existing sources of organizational funding and to establish newer frontiers. Specifically, there is need for engaging various stakeholders through communication and corporate social responsibility. The organization could widen the net to attract resources from private sector organizations and individuals. Efforts should be put in place to develop social enterprises that assist the organization in solving social problems while using business

\section{Suggestions for further research}

The study suggests that further studies can be undertaken on the efficacy of NGO resource mobilization plans. Since resource mobilization requires leadership, further investigations could be anchored on effectiveness of leadership styles on resource mobilization. With the advent of multimedia sources, social enterprise proponents feel that organizations should consider using the internet as a costless platform that allows the funder to give continuously.

Research efforts should be geared on establishing the success factors in internet fundraising. Further research work should investigate new approaches for NGO sustainability through public private partnership projects (PPPs).

\section{Reflection}

This presents a personal reflection of the author upon the learning experiences and presents a critical analysis of the challenges \& learning experiences as a result of conducting this study.

Throughout this study, the researcher has read \& analyzed relevant literature, articles, and previous research on topics relating to the variables of this study in order to gain understanding of the research phenomenon. The researcher has therefore gained a deeper understanding of the strategic management. It has greatly boosted the author's analytical skills. 


\section{References}

[1]. Aksel I, Baran M (2006). "Organizational Problems of Non-Governmental Organizations (NGOS)," the 3rd International NGO's Congress, December 9-10, Canakkale, Carneiro, J.M.T, Cavalcanti, M.A.F.D; SILVA, J.F. Porter Revisitado: A critical Analysis of the strategic Typology of the Master. Journey of Contemporary Management

[2]. Cleveland, C.J. and I. Kubiszewski (2007), "United Nations Conference on Environment and Development (UNCED), Rio de Janiero, Brazil", Encyclopedia of Earth, Retrieved 16 March 2009,

[3]. Cuthill (2010), United Nations Conference on Environment and Development (UNCED), Forum for the Future (2003), Reporting for Sustainability: Guidance for Higher Education Institutions, Forum for the Future, London

[4]. Fred R. David (2008), strategic management; concept and cases, 12th edition Gomes Joao and D. Livdan (2004). Optimal diversification: reconciling theory and evidence.

[5]. Gort, M (1962). Diversification and Integration in American Industry.

[6]. Hopkins, C. and R. McKeown (1999), "Education for Sustainable Development", FORUM for Applied Research and Public Policy, winter, pp. 25-29.

[7]. Helfat, C.E. and Eisenhardt, K.M., Inter-Temporal Economies of Scope, Organizational Modularity, and the Dynamics of Diversification. Strategic Management Journal 2004.

[8]. Hitt, M. A; IRELAND, R.D.; Hoskisson, R.E Strategic Management Competitiveness and globalization.

[9]. Jacobs (1999) .Education for Sustainable Development Toolkit. USA: Energy, Environment and Resource Center McKenzie (2004). Globalization and Education for Sustainable Development. Sustaining the Future. Nagoya, Japan Robèrt et al. 2002 Encyclopedia of Earth, [cited April 2, 2013

[10]. Montgomery, C.A. (1985). Product-market diversification and market power, Academy of Management Journal, 28

[11]. http://www.eoearth.org/article/United Nations Conference on Environment and Development (UNCED), Rio_de_Janeiro, Brazil.

[12]. Rumelt, R.P. (1974). Strategy, Structure, and Economic Performance.

[13]. Wernerfelt, B. \& Montgomery, C. (1988). Tobin's q and the importance of focus in firm performance.

[14]. Wernerfelt, B (1984). A resource based view of the firm. 